- ACORN Australan College peroperative nuRses | JOURNAL OF PERIOPERATIVE NURSING

\title{
Smartphones in the operating room: Can perioperative nurses be trusted?
}

Follow this and additional works at: https://www.journal.acorn.org.au/jpn

Part of the Perioperative, Operating Room and Surgical Nursing Commons (c) (i)

This work is licensed under a Creative Commons Attribution 4.0 License.

\section{Recommended Citation}

Armour, Tarryn and Coffey, Elyse (2021) "Smartphones in the operating room: Can perioperative nurses be trusted?," Journal of Perioperative Nursing: Vol. 34 : Iss. 1 , Article 3.

Available at: https://doi.org/10.26550/2209-1092.1114

https://www.journal.acorn.org.au/jpn/vol34/iss1/3

This Feature is brought to you for free and open access by Journal of Perioperative Nursing. It has been accepted for inclusion in Journal of Perioperative Nursing by an authorized editor of Journal of Perioperative Nursing. 


\section{Author}

Tarryn Armour

MClinEd, GradDipAdNrsgPrac (periop),

GCertHELT, BN, BaHthProm, RN, FACORN

Elyse Coffey

MNurs (Perian), GCertHELT, BN(Honours), RN

\section{Smartphones in the operating room: Can perioperative nurses be trusted?}

\section{Introduction}

The use of hand-held technology has become ubiquitous in modern life'. For many Australians, handheld technology is a necessity with nearly nine out of ten owning a smartphone ${ }^{2}$. Smartphones are now so powerful they can supersede the need to use any other digital device. In the clinical environment, smartphones offer a pocketsized, convenient and immediate means of accessing a wide range of information and resources on relevant topics such as medications, surgical procedures and equipment as well as access to organisational email communications and health care-related apps. While computers are available in many clinical areas, access is often constrained and their use remains dedicated to patient management systems, diagnostics, pathology, sterile tracking systems and, more recently, electronic medical records. As with previous technological advancements, the use of smartphones presents unique social and professional opportunities and challenges. How we choose to use - or not use - our smartphone is critical. The increasing availability and capability of handheld technology in health care requires a specialised workforce with an understanding of appropriate use of digital technology ${ }^{3}$. While there has been a rapid evolution in smartphone technology with widespread application in health care, the development of guidelines and policies to govern their use has been slow to follow4.

The recent publication of the National Nursing and Midwifery
Digital Health Capability Framework supports the safe and effective implementation of digital health in Australia. The framework also recognises that, increasingly, all nurses and midwives work in a digital environment and that it is essential for every nurse and midwife to have digital literacy skills to maximise health and societal outcomes, improve services and extend their evidence-based practice ${ }^{3}$. This requirement is clearly evident in the technologically dense perioperative environment where nurses are expected to intersect with digital technology as part of everyday provision of patient care. Advocating for digital literacy among nurses and the requirement to use technology for many patient care activities has been part of nursing practice for over a decade ${ }^{5}$, yet, within operating rooms, staff access to personal hand-held technology continues to be discouraged by management ${ }^{6}$. A lack of policy and difference between generations' perceptions regarding the use of personal hand-held devices has resulted in a persistent cultural overtone of distrust of their use in the clinical environment. Perhaps it is time to consider the use of hand-held technology by perioperative nurses in the operating room as a valuable resource to enhance patient safety and improve the delivery of patient care.

In order to explore this field, a review of the literature was conducted to identify the drawbacks to and benefits of access to hand-held technology in the clinical setting and to make recommendations for healthy technological behaviours in the perioperative environment. 


\section{Drawbacks to the use of hand-held technology}

Distraction has been identified in the literature as a major drawback to using hand-held technology in the clinical environment ${ }^{7-10}$. Distraction in the clinical environment can be defined as a direct interruption of a clinician's immediate task by using their smartphone. Distraction from using a smartphone in the clinical area can lead to perceived performance deficits in clinical staff; however, no evidence of any actual or potential patient harm was observed in two studies. McBride ${ }^{8}$ compared self-reported data to performance errors of registered nurses $(n=825)$ working in American health care organisations while Cambier examined the impact on workplace cognitive failure of registered nurses' mobile phones $(n=849)$ from three hospitals in Belgium.

Using a smartphone for reasons not related to work, such as engaging with social media or 'cyberloafing', is a potential cause of distraction ${ }^{10}$. McBride and colleagues suggest that this misuse of smartphone technology may be attributed to an inadequate understanding of digital professionalism by registered nurses. Digital professionalism is required to judge when it is appropriate to access smartphone technology ${ }^{8}$ and is a professional attribute that must be developed and modelled. It is argued that the increasing diversity of resources and information accessible via a smartphone results in uncertainty about whether this technology is being used for cyberloafing or for legitimate workrelated activities. This uncertainty often results in any smartphone use being misconstrued as a distraction. In addition to the use of smartphones being perceived as a distraction from clinical activities, other research reports health care worker concerns related to patient privacy and infection control risks as well as an overall discomfort with the hand-held devices being used in the clinical environment ${ }^{11}$. Two studies examined the concept of smartphone addiction and how this can affect therapeutic relationships in the clinical environment ${ }^{12,13}$. A common theme of these studies was that negative perceptions of smartphone use were commonly based on older generations' beliefs that smartphones were purely used for cyberloafing, rather than for seeking information related to patient care. Both studies recognised the need to develop strategies for preventing smartphone dependency and to promote healthy and safe use of smartphones to ensure appropriate, point-of-care access to clinical information and resources ${ }^{12,13}$.

A qualitative study by Mather et al. reports on interviews with representatives from professional nursing organisations aiming to explore the factors influencing the governance of hand-held technology used at the point of care for informal learning and continuing professional development (CPD). Themes such as access, negative perceptions of use and distraction highlight the complexity of using hand-held technology for informal learning and continuing professional development in the clinical setting. Giles-Smith et al. ${ }^{14}$ also explored nurses' use of hand-held technologies and showed that access to and use of smartphones is already occurring in the clinical setting with a lack of leadership, role modelling or professional guidance about how to support and foster positive use of this technology to enhance patient care $^{14}$. This finding is supported by Mather et al. who determined that not only is leadership in digital professionalism within hospital management lacking but that professional nursing organisations are also reluctant to exert agency and challenge traditional work patterns to advance protocols to govern digital professionalism. While a number of drawbacks to using hand-held technology in the clinical environment were apparent in the literature, the potential also exists for smartphones to be used to improve patient care and enhance quality and safety outcomes ${ }^{11,14}$.

\section{Considerations for the use of hand-held technology}

A major benefit of using smartphone technology in the clinical setting, that was identified in the literature, is mobile learning - a modality that has been strongly adopted in Australian tertiary education and within Bachelor of Nursing degrees. Mobile learning enables nursing students to seek and retrieve information in real-time and this can aid decision making, potentially improving patient outcomes ${ }^{15}$. However, uptake of mobile learning by stakeholders in health care environments, especially nurses, to augment traditional teaching and learning has been slow and digital knowledge transfer is under-utilised ${ }^{16}$. Access to and use of hand-held devices for learning at the point of care within Australian health care environments is poorly governed and is not an explicitly sanctioned nursing activity ${ }^{16}$. Despite much of the literature acknowledging the benefits of undergraduate nurses using hand-held technology for mobile learning $4,1,1,7$, along with many universities having graduate learning outcomes related to digital literacy and self-management, there exists the paradox of undergraduate nurses being discouraged from or not permitted to use handheld technology in the clinical environment. 
To examine the behaviour of undergraduate nurses when accessing information using handheld technology during clinical placement or work integrated learning (WIL), Mather and colleagues ${ }^{18}$ surveyed $(n=84)$ Australian undergraduate nurses and found that undergraduate nurses limited activity not related to work during WIL; only using their smartphones to access information related to nursing, medical professional development and study. Undergraduate nurses also expected easy access to their smartphones when working to ensure they delivered safe and competent care, a finding that is reflected in a number of other studies worldwide $4,1,2,4,17,19$. This access to and appropriate clinical use of smartphone technology needs to be reflected in the clinical environment and role modelled by those training novice nurses. It is argued that health care managers and nursing staff need to start advocating for the healthy use of smartphone technology in order to guide and support student nurses as well as model digital professionalism in the clinical setting 4,19.

\section{Recommendations}

Nurses comprise the largest health care workforce $^{3}$ and are consistently nominated as the most ethical and honest profession ${ }^{20}$. A dichotomy currently exists between being the most trusted profession in Australia, depended on to provide complex nursing care and administer controlled substances, yet not trusted to responsibly use smartphones in the clinical setting. On review of the literature, it is recommended that health care organisations develop policies for hand-held technology and provide guidance for its use in the clinical environment in order to encourage healthy technological behaviours, and infection prevention guidelines that serve to enhance patient care and promote positive patient outcomes.

In October 2020 the Australian government released the National Nursing and Midwifery Digital Health Capability Framework, which highlights the need for digital health training and education across Australia as well as encouraging positive attitudes to the increasing adoption of technology and innovation ${ }^{3}$. Prior to this, an analysis of many sources including government health recommendations ${ }^{21}$, the National Safety and Quality Health Service Standards ${ }^{22}$, Registered Nurse Standards for Practice ${ }^{23}$, Standards for Perioperative Nursing in Australia ${ }^{24}$ and the Nursing and Midwifery Board of Australia Code of Conduct for Nurse ${ }^{25}$ revealed an absence of guidance to support digital responsibility in health care despite the World Health Organization endorsing the use of digital, mobile and wireless technologies to achieve heath objectives and improve patient care outcomes ${ }^{26}$.

As smartphones are readily available to all staff in the operating room and commonly used, nursing management should recognise the benefits of this technology in the perioperative environment and guide perioperative nurses to learn digital professionalism. Importantly, this should encompass the need to understand, develop and demonstrate appropriate behaviour when using smartphones ${ }^{3}$. For mobile learning and access to clinical information related to patient care using smartphones in the perioperative setting to be perceived as a legitimate nursing function, a holistic approach to risk management that includes all stakeholders, at all levels, is required. The goal should be to develop organisational policy that establishes a better balance between the costs and benefits of access to hand-held technology in real-time by perioperative nurses ${ }^{1,19}$. A digitally capable workforce will be able to guide the new generation of nurses to become digitally professional and minimise the potential risks, such as distraction, associated with using hand-held technology.

\section{Conclusion}

Hand-held technology, such as smartphones, provide a pocket-sized and instant means of accessing information and resources related to patient care. The drawbacks that limit the use of hand-held technology include potential distraction from clinical activities, smartphone addiction, negative perceptions that smartphones will be used for activities not related to work such as cyberloafing, interference to patient privacy and infection control risks. Conversely, the benefits of using hand-held technology include enhanced mobile learning at the point of care, easy and instant access to information and efficacious communications across hospital departments and professions. It is recommended that hand-held technology as part of perioperative nurses' digital literacy, learning and work enhancement be accepted and policies be developed to guide responsible use within the operating room. Perioperative teams looking to allow smartphone use should consult evidence-based practice standards for their safe use in perioperative care settings. Additionally, further research into the current use of digital technology in specific clinical settings such as the operating room, including usage modes, frequency and timing of use, and the impact on patient care, is recommended. 


\section{References}

1. Mather CA, Cummings EA, Gale F. Advancing mobile learning in Australian health care environments: Nursing profession organisation perspectives and leadership challenges. BMC Nursing 2018;17(1).

2. Deloitte Access Economics. Mobile Nation 2019: The $5 \mathrm{G}$ future [Internet]. Canberra: Australian Mobile Telecommunications Association; 2019 [cited 2021 February 1]. Available from: https://www2.deloitte.com/ content/dam/Deloitte/au/Documents/ Economics/deloitte-au-economics-mobilenation-2019-080419.pdf.

3. Australian Digital Health Agency. National Nursing and Midwifery Digital Health Capability Framework 2020 [Internet]. Canberra: Australian Government; 2020 [cited 2021 February 1]. Available from: https://www.digitalhealth.gov.au/sites/ default/files/2020-11/National_Nursing and_Midwifery_Digital_Health_Capability Framework_publication.pdf.

4. Joseph A, Nair D, Jojo J, Majeed S, Aranha PR. Use of mobile phone for academic purpose among nursing students: A cross sectional study. Indian J Public Health 2020;11(4):38-44.

5. Booth RG. Educating the future eHealth professional nurse. Int J Nurs Educ Scholarsh 2006;3(1):1-12.

6. Guglielmi CL, Banschbach S, Dort J, Ferla B, Simon R, Groah L. Hand-held communication cevices: Friend or foe? AORN J 2013;98(3):294-303.

7. Rivera-Rodriguez AJ, Karsh BT. Interruptions and distractions in health care: Review and reappraisal. Qual Saf Health Care 2010;19(4):304-312.

8. McBride D, LeVasseur SA, Li D. Nursing performance and mobile phone use: Are nurses aware of their performance decrements? JMIR Human Factors 2015;17(4):e6. DOI: 10.2196/ humanfactors.4070.

9. Cambier R, Van Laethem M, Vlerick P. Private life telepressure and workplace cognitive failure among hospital nurses: The moderating role of mobile phone presence. J Adv Nurs 2020;76(10):2618.
10. Hranchook AM, Penprase BB, Piscotty RJ. Mobile computing devices in the perioperative environment: A survey exploring uses and experiences among certified registered nurse anesthetists. AANA 2018;86(6):471-478.

11. Sergeeva A, Aij K, van den Hooff B, Huysman M. Mobile devices in the operating room: Intended and unintended consequences for nurses' work. J Health Inform 2016;22(4):11011110.

12. Cerit B, Çıtak Bilgin N, Ak B. Relationship between smartphone addiction of nursing department students and their communication skills. Contemp Nurse 2018;54(4-5):532-542.

13. Kaur A, Kaur R, Kaur R. Mobile phone usage among nursing students: A boon or bane for mankind. Nursing \& Midwifery Research Journal 2016;12(1):9.

14. Giles-Smith L, Spencer A, Shaw C, Porter C, Lobchuk M. A Study of the impact of an educational intervention on nurse attitudes and behaviours toward mobile device and application use in hospital settings. JCHLA 2017;38(1):12-29.

15. Lall P, Rees R, Law GCY, Dunleavy G, Cotič $\check{Z}$, Car J. Influences on the implementation of mobile learning for medical and nursing education: Qualitative systematic review by the digital health education collaboration. J Med Internet Res 2019;21(2):e12895.

16. Mather C, Cummings E. Empowering learners: Using a triad model to promote eHealth literacy and transform learning at point of care. KM\&EL 2015;7(4):629-645.

17. Sheikhtaheri A, Hashemi N, Hashemi N-a. Benefits of using mobile technologies in education from the viewpoints of medical and nursing students. Stud Health Technol Inform 2018;251:289.

18. Mather C, Cummings E, Allen P. Nurses' use of mobile devices to access information in health care environments in australia: A survey of undergraduate students. JMIR mHealth and uHealth 2014;2(4):e56.

19. Pimmer C, Brysiewicz P, Linxen S, Walters F, Chipps J, Gröhbiel U. Informal mobile learning in nurse education and practice in remote areas-a case study from rural South Africa. Nurs Educ Today 2014;34(11):1398-1404.
20. Health Workforce Australia. Australia's health workforce series: Nurses in focus 2013 [Internet]. Adelaide; Health Workforce Australia; 2013 [cited 2021 February 1] Available from: http://hdl.voced.edu. au/10707/258616.

21. NSW Health. Use of Personal Mobile Phones or Communication Devices and Phone Call/ Telephone Management in the Workplace [Internet]. Sydney: NSW Government; 2015 [cited 2021 February 1]. Available from: http://www.hnehealth.nsw.gov.au/Careers/ Documents/PD2015_049_PCP_2_Use_of_ Personal_Mobiles_or_Communication_ Devices.pdf.

22. Australian Commission on Safety and Quality in Health Care (ACSQHC). National safety and quality health service standards. 2nd ed. [Internet]. Sydney: ACSQHC; 2017 [cited 2021 February 1]. Available from: www.safetyandquality.gov.au/standards/ nsqhs-standards.

23. Nursing and Midwifery Board of Australia (NMBA). Registered nurse standards for practice [Internet]. Canberra: NMBA; 2016 [cited 2021 February 1]. Available from: www.nursingmidwiferyboard.gov.au/CodesGuidelines-Statements/Professionalstandards/ registered-nurse-standards-forpractice.aspx.

24. Australian College of Perioperative Nurses (ACORN). Standards for perioperative Nursing in Australia $16^{\text {th }}$ ed: Volume $1-$ Clinical Standards. Adelaide: ACORN; 2020.

25. Nursing and Midwifery Board of Australia (NMBA). Code of conduct for nurses [Internet]. Canberra: NMBA; 2018 [cited 2021 February 1]. Available from: www.nursingmidwiferyboard.gov.au/CodesGuidelines- Statements/Professionalstandards.aspx.

26. World Health Organisation (WHO). WHO guideline: Recommendations on digital interventions for health system strengthening [Internet]. Geneva: WHO; 2019 [cited 2021 February 1]. Available from: https://apps.who.int/iris/bitstream/ handle/10665/324998/WHO-RHR-19.7-eng. 